As a possible cause of the dermatitis, it should be said that the patient had been in the Catskill Mountains five days before the eruption appeared. She did not, however, handle any poison ivy leaves. She had never previously suffered from rhus poisoning to her knowledge, though it must be said that during the greater part of her adult life she had lived in Germany.

The patient appeared to be susceptible to irritation from plants, as on a previous occasion (end of June) she had handled sanguinaris powder and on the following day an eruption had appeared on the face, neck and chest, and between the fingers. It was red and showed "blisters," and lasted ten days. This attack also followed a short walk in the country (three days previously) though she did not, as far as she was aware, come in contact with poison ivy. Very recently she had again suffered from a slight eruption on the wrists, on the day after she had handled pistachio nuts. This lasted only two days. On this occasion she had immediately used alcohol and zinc oxid ointment.

The oriental cashew nut, which was presumably the cause of the dermatitis in this case, is to be distinguished from the cashew nut which is a native of tropical America (Anacardium occidentale). The oriental, like the native species, is known to be a cutaneous irritant.

\title{
DISCUSSION
}

Dr. WISE inquired concerning the five days' incubation period of poison ivy.

Dr. Fox replied that the eruption came on very suddenly after the exposure. He had never seen a case in which the incubation period lasted five days.

Dr. Winfreld said that he had had personal experience. On some occasions the eruption did not develop for ten days to two weeks after exposure, although there was considerable itching before the eruption appeared.

Dr. WISE said that he had seen a case in a clinic on a Monday in a man who stated that he had been in the woods on the preceding day, Sunday, that is. seven days previously.

Dr. Highman told of a patient seen on a Wednesday, the exposure having occurred on the previous Sunday, or four days earlier.

\section{PHILADELPHIA DERMATOLOGICAL SOCIETY}

Regular Monthly Meeting, Nov. 8, 1920

Milton B. Hartzel., M.D., Presiding

\section{MYCOSIS FUNGOIDES. Presented by Dr. Hartzell.}

A printer, 50 years old, had a universal dermatitis for over two years. In most situations it exhibited a smooth, shiny red infiltration, itchy and slightly scaly, the latter condition being most marked on the palms. Significant features of the disease were numerous eruptions on the trunk in the form of scores of flat, infiltrated, slightly elevated, scaly areas ranging from the size of a pea to that of a fingernail. These tumors had been present for the past four months. They were most abundant on the upper trunk, both anteriorly and posteriorly. Adenopathy was marked; the inguinal and axillary glands stood out in relief. No laboratory findings were reported. A moderate degree of conjunctivitis was present. 


\section{DISCUSSION}

DR. SCHAMBerg agreed with the diagnosis and regretted that no blood count had been made on account of the resemblance of this disease to leukemia of the skin.

\section{Xeroderma PIGMentosum. Presented by Dr. Schamberg.}

This boy of 13 had been under observation for eight years. During this time several carcinomas were removed from his face by means of the actual cautery. Two years ago a mushroom-like growth of myxomatous character was excised from the scalp. Two brothers had the disease. The patient exhibited extreme photophobia due to corneal ulceration. Freckle-like lesions were present on the conjunctiva and in large numbers on the skin. Several carcinomatous growths were present, the largest being near the right corner of the mouth. The patient's mental condition had improved, and he was not as depressed as formerly.

The action of the sun on these cases might be likened to that of the roentgenray bulb, but the use of the latter was justified in treating localized areas of this disease.

\section{A CASE FOR DIAGNOSIS. Presented by Drs. Munson and Strauss.}

A white woman, aged 25 , married, had a more or less generalized itchy eruption, which had been present for four and a half years. The lesions were transitory, remaining for from a week to a month. Recently pigmentation had appeared on the parts most affected-the neck, upper chest, the inner side of the upper arm, abdomen and groins. The lesions were discrete, rounded, slightly elevated, flat papules or wheals, somewhat shiny in some situations. There was no mucous membrane involvement.

\section{DISCUSSION}

Dr. Schamberg thought this might be a case of lichen planus. He would have sodium cacodylate administered as a therapeutic test.

Dr. Strauss felt that the pigmentation might be the result of thyroid extract given this patient.

KAPOSI'S SARCOMA. Presented by Dr. Schamberg.

A white man, aged 64, was the subject of this disease of three years' duration. Both legs were involved from several inches above the knee to the sole. The color of the affected parts was of a deep bluish red. There was considerable edema below the knees and the patient suffered pain, especially when walking. Improvement followed roentgen-ray therapy so that the characteristic appearance was gone, but there were still some distinct small bluish nodules on the sole of each foot. A number of small sessile tumors were present between the ankle and knee of each leg.

\section{DISCUSSION}

Dr. HARTzell agreed with the diagnosis but considered the use of the word sarcoma unfortunate in this disease, so unlike the surgical sarcoma. Dr. Schamberg suggested angiosarcoma as a preferable term on account of the vascular element. 


\section{MACUlar atrophy. Presented by Dr. Hartzell.}

A middle-aged white woman had been under the speaker's observation for the past two weeks. She had an extraordinary condition which had existed for two years, resembling many of the cases reported as macular atrophy though it is not certain that all the cases so labeled are truly that disease; some are associated with scleroderma. The condition in this case may have been related to scleroderma. Numerous macules were located on the face, neck, shoulders, upper chest and back, varying in size from that of a pea to that of a postage stamp. Interspersed were as many pits formed by depressed atrophic areas of skin. The macules were waxy in appearance, the atrophic spots a dead white, giving the affected region a mottled look. It resembled numerous small scars. There was some itching, but it was not intense. On the back appeared slight scaling on the macules, which were barely elevated, infiltrated and firm.

\section{DISCUSSION}

Dr. Schamberg felt that this case was properly classified. The appearance of macular atrophy was produced during the transition from the indurated to the diffuse form of the disease.

PAPUlONECROTIC TUBERCULID. Presented by Dr. Warren. Walker.

A white boy, aged 12, presented dystrophia unguium involving all nails of all extremities. Two brothers and a grandfather were similarly affected. Several small circumscribed crusted areas were present on the dorsum of each hand, and the palms showed horny papules with hard centers closely resembling papulonecrotic tuberculid. These had been present since the age of 2 years. Some were quite flat, and nearly all showed the hard central plug. One brother had had a similar eruption for some years, but the disease had cleared up in his case.

ECZEMA. Presented by Dr. Maurice Brown.

A white girl, aged 8 , showed a crusted eruption involving principally the neck and extremities. This condition appeared when the patient was 4 months old and had persisted obstinately ever since with the exception of short remissions following acute infections. There was much thickening of the integument in the affected areas with crusting and fissuring, chiefly on the extensor surfaces. The skin elsewhere was dry and harsh and resembled that of ichthyosis. The diagnosis was eczema with, most probably, an underlying ichthyosis. The case was exhibited mainly to show the inveterate character of the eczema, which had resisted many forms of treatment.

LICHEN PLANUS. Presented by Dr. Brown.

A comparatively noninflammatory eruption on the forearm, arm and neck was present in a white boy of 7 years. At the base of the neck were small annular lesions, and on the flexor surface of the forearm typical lichen papules were to be seen. There was some linear grouping. The eruption caused an itching sensation. 


\section{heterochromia Pilorum. Presented by Dr. Clarence K. Dengler.}

A white boy, 8 years old, showed an unusual condition which had been present since birth. Most of the hair of the scalp was of a chestnut color but from a small area of scalp on the vertex, irregular in outline but about the size of a quarter dollar, grew hair of a bluish-black hue. The appearance of the scalp in this region was normal; there was no nevus or a pathologic process discernible. The impression conveyed was that of a smear of ink on the surface of blond hair. Both parents had dark hair.

\section{DISCUSSION}

Drs. Hartzell and Schamberg did not recall a similar case.

EPITHElioma. Presented by Dr. Warren Walker.

The age of this patient, 27, and the appearance of the lesion on his lip would at first glance have made the observer think of chancre which the history of four years' duration, gradual extension from a small beginning and absence of concomitant syphilitic signs, as quickly dispelled. He had served in the army while having the disease and had been under the observation of the presenter over two months. Adenopathy of the glands of the anterior chain was noted. The patient smoked considerably and had the habit of biting his lower lip, which possibly accounted for the somewhat atypical appearance and swelling.

\section{PRURIGO NODULARIS (?). Presented by Dr. Strickler.}

Following an operation for hernia seven years ago, a man of 50 developed small nodules in his skin, causing intense itching, confined to the arms, legs and trunk. Macroscopically the disease closely resembled prurigo, although the course was quite unlike that condition. The Wassermann reaction was negative and examination of the blood shed no light on the condition. The tuberculin test was also negative. A biopsy was made.

NEVUS UNIUS LATERIS. Presented by Dr. Knowles.

A white girl, aged 5 , in good health in other respects, presented an eruption on the right lower leg, none of the growths being above the lower margin of the knee cap. The patches were brownish, slightly elevated, infiltrated and sharply marginated. While irregular in outline, they were rather elongated in shape. The surface was slightly scaly. The condition had been present since infancy.

\section{HERPES ZOSTER AND SYPHILIS. Presented by Dr. Brown.}

On the left side of the chest of a white man, aged 48 , were several areas of redness and pigmentation marked with numerous small pitted scars. These patches swept downward and outward from the spine in the regular zosteriform distribution, but were unusually large. There was present in the right axilla a small patch of a somewhat different character. The right buttock showed an ulcerating gumma, and the Wassermann reaction was weakly plus. All the eruptions have improved as the patient was on antisyphilitic treatment, and the scarring from the zoster has faded in color. 
PITYRIASIS ROSEA. Presented by Dr. Greenbaum.

A man of early middle age, apparently Jewish, exhibited on the trunk, upper arms and thighs a number of slightly scaly, rounded patches the size of half a dollar, pinkish to salmon in color and with slight infiltration. Interest lay in the fact that the rings seemed anesthetic to the pin test. The duration of the condition was only three weeks.

\section{DISCUSSION}

Dr. Hartzell considered the case one of pityriasis rosea with hysterical anesthesia.

LYMPHANGiOMA. Presented by Dr. Schamberg.

A white girl, aged 17, showed a rounded, elevated lesion on the buccal mucous membrane. It was first noticed during her first year. It was reddish, firm but compressible and sharply circumscribed.

\section{CASES FOR DIAGNOSIS. Presented by Dr. Schamberg.}

A generalized eruption was present in a mulatto woman aged 29. Only the head and lower part of the legs escaped. For sixteen years she had been affected with a severely itching, papular eruption. No vesicles were seen or known to have been present, but most of the primary lesions were destroyed by scratching. Many excoriations and some pigmentation existed on the trunk. The causation was indefinite and diagnosis was witheld.

A former farm-hand. a negro 48 years of age, complained of intense itching for the past eighteen months. His arms and body presented numerous infiltrated lesions which resembled prurigo nodules in size and feeling, but a great part of the intervening skin was thickened and horny. The papules likewise had a horny covering. The lymph nodes in the axillae, neck and groins were quite prominent, some being the size of an egg. There was a leukocytosis of 60,000 with eosinophilia, but no lymphocytosis.

\section{ECZEMA FROM TYPHOID INOCULATION. Presented by Dr. Greenbaum.}

A young man, a fireman, developed an eczema of the hands two years ago, the disease coming on three weeks after the completion of typhoid prophylaxis. Desensitization by small doses of typhoid vaccine caused the eruption to disappear, and it was later reproduced by a full dose. The second attack occurred four months ago, and has not responded to desensitization. There was an edematous condition out of proportion to the superficial character of the eruption. The hands were puffy and the fingers swollen.

CASE fOR Diagnosis. Presented by Dr. Greenbaum for Dr. Schamberg.

. A white woman, aged 55, presented a condition which was first noticed two years ago. The lesions were located on her lower legs and forearms. A bleb the size of a half dollar was present on one lower leg and a smaller one on her left forearm. Numerous circumscribed atrophic areas were noted roughly corresponding in size to the bases of the bullae. The latter showed no tendency to spontaneous rupture and some seemed to dry up unbroken. They pursued a slow course, leaving a distinct atrophy at their site. There was no pain, no mucous membrane involvement and no internal medication which might have been responsible for the outbreak. Biopsy was not permitted. 


\title{
PHILADELPHIA DERMATOLOGICAL SOCIETY
}

\author{
Regular Monthly Meeting, Dec. 13, 1920
}

Milton B. Hartzell, M.D., presiding

\section{LYMPhangioma. Presented by Dr. Hartzell.}

A white boy, 9 years of age, born in Hungary, was brought to the Skin Dispensary of the University of Pennsylvania Hospital several weeks ago with an eruption in the left lumbo-abdominal region. There was a history of a unilateral, grouped vesicular outbreak preceded by pain and, as an appearance of crusts grouped in zosteriform fashion was present, it was thought to be a case of shingles. A mild ointment to soften the crusts was prescribed, and the surface cleared. At a subsequent visit a new crop of blisters had developed, antedated by pain in that region, according to the mother. An old transverse linear scar, about 5 inches long, formed the equator of the largest patch of vesicles, and beneath this region was felt a deep-seated doughy mass the size of two palms. The scar was caused by an operation performed in Hungary. The vesicles occurred in two or three other patches in the same region. Most of them were coalescing and were not easily ruptured. A few were the color of normal skin, but the greater number were pinkish, darkening to purple. The superficial condition was a lymphangiectasis, the deep one a lymphangioma. The recent history was at first misleading.

\section{DISCUSSION}

Dr. Schamberg agreed with the diagnosis. Lymphangiomas of the skin were often associated with fibrous tissue in the deeper parts and were mixed growths, fibrolymphangiomas.

Dr. HarTzell once had a patient with a similar condition, who was illadvised to open some of the vesicles, thus starting a flow of lymph which persisted for several days, soaking dressings and clothes.

\section{A CASE FOR DiAgnosis. Presented by Dr. Hartzell.}

A white woman, aged 50, exhibited an eruption of about twenty years' duration. It began as areas of scaliness scattered over the body, more or less generally, in the situations in which infiltrated red patches later developed. The latter were large and frequently palm-sized, some even larger and none smaller than the outline of an egg. Probably thirty were present. They were not sharply marginated, were considerably scaly and but slightly itchy. The scalp was clear, as were the hands and feet. Several patches had undergone spontaneous involution, atrophy and wrinkling of the skin resulting. The intermammary cleft and the mesial aspects of both breasts showed a sharply marginated, raised plaque of a brighter red color. This was probably a keloid, as the patient gave a history of a burn there when a child. A biopsy was made, but the report has not yet reached the presenter. The Wassermann reaction was weakly positive. The patient received some arsphenamin therapy, and stated that the scaliness had improved since then. No tumors existed.

\section{DISCUSSION}

Dr. Schamberg considered this case rather remarkable. There was enough infiltration present to rate it as a neoplasm. He thought it might be an anomalous type of parapsoriasis. 
Dr. KNowles said that mycosis fungoides was suggested when he first saw the case.

Dr. HARTzell said that the spontaneous involution and atrophic scarring certainly suggested granuloma fungoides. There was marked infiltration.

Atrophoderma PEMPhigoldes. Presented by Dr. Greenbaum (Dr. SCHAMBERG).

The case shown at the November meeting, that of a Jewish woman of 55, with lesions, apparently blebs, followed by atrophy, was shown again. New bullae had formed on the lower legs and left forearm. They were brownish in color and flaccid, though tense when first noted. They were deep-seated and had a thick roof, as evidenced by venules present in the latter. As they progressed the fluid was absorbed and the fibrous tissue of the floor of the bleb atrophied, so that when this had occurred the examining finger felt, as it were, a buttonhole in the skin. It was not absolutely certain that the lesions contained fluid, but the patient said that she pricked one and obtained a bloody liquid. She would not permit one to be opened by a physician. The name atrophoderma pemphigoides appeared to be appropriate.

\section{DISCUSSION}

DR. HARTZell remarked on the similarity of the atrophy to that seen in some cases of leprosy-not intimating that this case had any other suggestion of that disease.

DR. Schamberg said he had never seen this picture before in all its aspects. The blebs when seen early were tense, but later became wrinkled, as though the contents were absorbed.

Dr. Greenbaum spoke of the new bleb on the forearm. It had appeared since the last meeting and had been noted throughout its course.

\section{EPITHeliomas. Presented by Dr. Pfahler.}

A white patient, aged 57 , began to receive treatment for an epithelioma of the glans penis the last of August, 1920. It had been noted three months earlier. He was treated with radium; $100 \mathrm{mg}$. were applied over the growth and $50 \mathrm{mg}$. in the urethra beneath it. The time of exposure in each of the three positions was two hours. The neoplasm disappeared without loss of tissue. In two months there was no sign of return. The roentgen ray was used over the groins for the control of metastases.

The second patient was a man of about the same age, who began to receive treatment Sept. 23, 1920, for epithelioma of the end of the tongue. There was distinct glandular enlargement. Radium was used on the surface and by needles in the substance of the growth. The roentgen ray was used externally, and later the radium applications were renewed. The growth and the glandular enlargements have both disappeared.

\section{A CASE FOR DIAGNOSIS. Presented by Dr. A. Strauss.}

A white man, aged 40 , exhibited a generalized eruption. It seemed to begin, according to the history given by the patient, as an urticarial rash, which in the course of five months appeared as rather small, flat shiny papules. They were quite discrete, well scattered and showed abraded tops from scratching. 
Excoriations abounded among the lesions. There was an indistinct tendency to dermatographism. The lesions were most pronounced on the trunk, arms and thighs. Itching was intense.

\section{DERMATITIS HERPETIFORMIS. Presented by Dr. Warren Walker.}

The eruption on the patient, a white man of 56 , began as a bullous erythema multiforme about six months ago. The backs of the hands, neck and face were affected and the outbreak seemed to be a typical one. Instead of clearing completely, however, an eruption of a different type began on the trunk, arms and legs as a sudden widespread efflorescence of papules and vesicles, changing the appearance to that of dermatitis herpetiformis. The lesions were thickly set and often pigmented. They were transient and came out in successive crops. The case was a hospital case, and the patient resisted treatment for some time. The itching was severe and many excoriations and abraded papules, mainly on the back, were present. The grouping was not especially characteristic. Under treatment with cacodylate of soda given hypodermically there had recently been some improvement.

\section{MYCOSIS FUNGOIDES. Presented by Dr. Strickler.}

A white man, aged 42 , had a typical premycotic case of this disease. Scaly red, infiltrated plaques, varying in size from that of a silver dollar to that of two palms, were numerous on nearly all parts. There was some itching. None of the areas had disappeared recently. Arsenicals were being used, but the disease was practically stationary.

\section{PARAPSORIASIS. Presented by Dr. Hartzell.}

The speaker had recently seen three cases which bore a distinct resemblance to one another. They were rather hard to classify. All bore some resemblance to syphilis, and the patients had been treated for that disease, though they had negative Wassermann reactions. The patient exhibited, a white man of about 30 years, had had the disease for four years. The Wassermann reaction had been negative on three different occasions. A series of three arsphenamin injections had produced no improvement. The condition began as red maculopapules, which later developed scales. There was no itching. Cervical adenopathy was present.

\section{DISCUSSION}

DR. KLAUDER remarked that the case appeared to be one of parapsoriasis.

DR. Schamberg said it bore resemblance to pityriasis lichenoides.

DR. Hartzell added that a biopsy had been of no assistance in determining the type. There was no eruption in the palms of this patient, but there had been in the palms of others of the series. The eruption was macular at first. While he called it parapsoriasis, he deplored the name as it was used to cover a number of unrelated conditions.

\section{ARSPHENAMIN DERMATITIS. Presented by Drs. Schamberg and KLAUDER.}

A young, white woman, after receiving two injections of arsphenamin less. than a week part, suddenly developed an erythematous eruption which came out a week after the last injection. It was more or less generalized but was 
most severe on the neck and chest. The duration was three days. At first it was morbiliform in appearance. An injection had extravasated, produced cellulitis and induration, and it was felt that she had been sensitized thereby.

\section{CHICAGO DERMATOLOGICAL SOCIETY}

Regular Meeting, Nov. 17, 1920

Clarence A. Baer, M.D., Presiding

LICHEN PLANUS ATROPHICUS ET SCLEROSUS. Presented by Dr. FISCHKIN.

The patient was a woman, aged 26 years, with white, atrophic spots, intermingled with flat papules surrounded by a vermilion border on the neck, chest and shoulders, which had been present for three months.

\section{DISCUSSION}

Dr. Lieberthal thought the case was a fine example of lichen planus atrophicus.

\section{MOELLER'S GLOSSITIS OR GEOGRAPHIC TONGUE. Presented by} Dr. Stillians.

A Jewess, aged 23 years, married, had had pulmonary tuberculosis in 1918 and 1919, but left the sanatorium in good condition in 1919. In January, 1920, the sides of her tongue became sore and rough, and ring-shaped lines appeared, which changed position from day to day. The tongue gradually grew more painful, and the condition interfered greatly with eating, being irritated especially by acid foods, hot, spicy or hard foods. Salt produced much irritation.

The sides of the tongue were rough with deep fissures, in some of which could be seen short segments of the yellowish lines seen on the surface. These lines were about $2 \mathrm{~mm}$. in width, dull yellowish-white, slightly elevated, disposed in short segments, and were more or less curved. At the sides and lateral part of the dorsum were smooth areas from which the filiform papillae had disappeared while the circumvallate papillae remained. Some of the smooth areas were crossed by the yellowish lines. General examination had revealed a hyperthyroidism and intestinal intoxication, and the patient has improved on a strict diet. She had received one short period of radium therapy which she thought relieved the pain a great deal.

\section{DISCUSSION}

Dr. Senear was inclined to disagree with the diagnosis of Moeller's glossitis. The appearance of the margins of the tongue was not in keeping with Moeller's glossitis, as there were patches with whitish margins which he felt were typical of lingua geographica. He had recently seen the last case of Moeller's glossitis reported by the late Dr. Harris and had found the patient suffering intense discomfort, especially when eating. He had recommended the retirement of the man from railway service, although the clinical appearance of the condition was so insignificant that he felt that medical officials of the company might be skeptical. 